
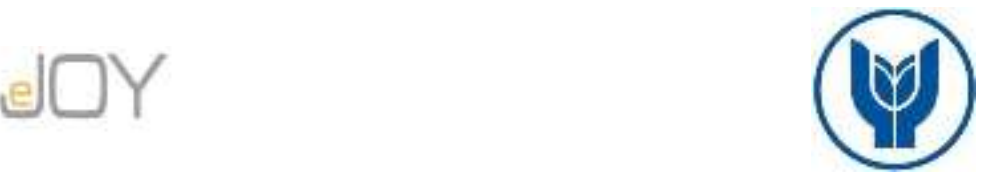

Konat, G. / Journal of Yasar University, 2021, 16/61, 348-360

\title{
Sağlık Harcaması ve Ekonomik Büyüme İlişkisi: OECD Ülkeleri İçin Panel Veri Analizi
}

\section{Health Expenditure and Economic Growth Relationship: Panel Data Analysis For OECD Countries}

\author{
Gökhan KONAT, Bolu Abant İzzet Baysal Üniversitesi, Türkiye, g_konat@ hotmail.com \\ Orcid No: 0000-0002-0964-7893
}

\begin{abstract}
Öz: Beşeri sermayenin ekonomik büyüme ile ilişkisi son yıllarda sıklıkla incelenen bir araştırma konusudur. Beşeri sermaye sağllk gibi en temel bir ihtiyaç göstergesini içinde barındırmaktadır. Bir toplumu meydana getiren bireylerin sağlık düzeylerinin yüksek olmasl, o toplumun ekonomik anlamda gelişme potansiyelini artırmaktadır. Să̆llklı bireyler yetiştirmek ve bireylerin sağllk düzeylerini korumak amacıyla gerçekleştirilen sağllk harcamalarl, beşeri sermayenin niteliğini artıran faktörlerin başında gelmektedir. Sağlık harcamalarının beşeri sermayeye sağladiğl olumlu katkılar, ekonomik büyüme için ciddi bir kaynak oluşturmaktadır. Bu çalışmayla, seçilmiş 17 OECD ülkesi için sağllk harcamaları ve ekonomik büyüme arasındaki ilişki incelenmektedir. Yapılan ampirik analizde söz konusu ülkeler için 1976-2017 yıllarını kapsayan dönemde cari fiyatlarla kişi başı sağlık harcamaları ve kişi başı GSYIH verileri kullanılmıştır. Sağlık harcamaları serisi için veriler OECD resmi veri tabanından derlenmiştir. Ekonomik büyüme verileri ise Dünya Bankası resmi veri tabanından temin edilmiştir. Seriler arasındaki saklı eşbütünleşme ilişkisi Hatemi-J (2018) tarafindan önerilen test ile sınanmıştır. Seriler kendi aralarında uzun dönemli ilişkiye sahip değilken, pozitif ve negatif şoklar arasında uzun dönemli ilişki bulunmuştur. Ayrıca serilerin asimetrik nedensellik ilişkisi sınanmış ve serilerin negatif şokları arasında çift yönlü bir nedensellik ilişkisi tespit edilmiştir.
\end{abstract}

\section{Anahtar Kelimeler: Să̆lık Harcaması, Ekonomik Büyüme, Panel Veri, Saklı Eşbütünleşme, Asimetrik Nedensellik}

\section{JEL Siniflandirmast: 115, O11, C40}

\begin{abstract}
The relationship of human capital with economic growth is a research topic that has been frequently studied in recent years. Human capital contains a basic need indicator such as health. The high level of health of individuals who make up a society increases the economic development potential of that society. Health expenditures to raise healthy individuals and maintain their health levels are among the factors that increase the quality of human capital. The positive contributions of health expenditures to human capital constitute a serious resource for economic growth. This study examines the relationship between healthcare spending and economic growth for selected 17 OECD countries. In the empirical analysis conducted, per capita health expenditures and GDP per capita data were used for the mentioned countries in the period covering 1976-2017. Data for the health expenditure series has been compiled from the OECD official database. Economic growth data were obtained from the World Bank official database. The hidden cointegration relationship between the series was tested with the test proposed by Hatemi-J (2018). While the series did not have a long term relationship among themselves, a long term relationship was found between positive and negative shocks. In addition, the asymmetric causality relationship of the series was tested and a bidirectional causality relationship was detected between the negative shocks of the series.
\end{abstract}

Keywords: Health Expenditure, Economic Growth, Panel Data, Hidden Cointegration, Asymmetric Causality

JEL Classification: 115,011, C40

\section{Giriş}

Beşeri sermaye kavramı literatürde çeşitli tanımlara sahiptir. Kısaca kişilerin ya da toplumların bilgi, beceri, yetenek, sağlık durumu, toplumsal ilişkilerdeki yeri ve eğitim düzeyi gibi kavramları içinde bulunduran geniş kapsamlı bir tanımlama yapılabilir. Beşeri sermaye 
olgusunun temelinde insan yer almaktadır. Bu bağlamda beşeri sermaye günden güne önem kazanmaktadır. Dolayısıyla gelişmiş ve gelişmekte olan ülkeler adına hem stratejik bir üretim faktörü, hem de iktisadi kalkınmanın vazgeçilmez bir unsuru halindedir (Yılmaz ve Danışoğlu, 2017).

Sağlık ve eğitim beşeri sermayenin kaynağını oluşturmaktadır. Sağlık, ekonomik büyüme üzerinde önemli bir etkisi olabilecek unsurlardan biridir. Sağlık düzeyi yüksek bir toplumun beşeri sermayeyi beslemesinde ve gelişmesine önemli katkıda bulunacağı aşikârdır (Ağır ve Tıraş, 2018). Bir toplumun sağlık alt yapısının yüksek olması nitelikli insan potansiyelini arttıracaktır. Dolayısıyla o toplumun kalkınması için de artı bir öneme sahip olduğu anlamına gelecektir.

Aileler, şimdiki ve gelecek nesillerin işgücü kalitesini artırma kapasiteleri üzerinde doğrudan ve dolaylı olarak etkilidir. Böylece beşeri sermaye birikimine katkıda bulunacak olan tüketim ve üretim kapasitelerine bağlı olarak sağlıkları ile ilgili birçok seçim yapmaktadır (Antonio ve Zamora, 2000). Sağlık olgusunun toplumun gelir ve refahı, işçi verimliliği, işgücü katılımı, tasarruf ve yatırım oranları, demografik faktörler ve diğer beşeri sermaye faktörleri üzerinde doğrudan ya da dolaylı etkileri mevcuttur. Bu bağlamda bu olgu bireylerin sahip olduğu en değerli varlık olarak kabul edilir. Nitekim sağlık, sadece hastalık ve sakatlığın olmaması değil aynı zamanda bireylerin tüm yaşamı boyunca kendi potansiyelini geliştirme kapasitesini ifade etmektedir (Lustig, 2006).

Çoğu iktisatçı, bir ülkeyi nihai olarak belirleyen ekonomik ve sosyal kalkınma sürecinin, o ülkenin insan kaynaklarının ve büyüme sürecinde beşeri sermayenin öneminin fiziksel sermaye kadar önemli olduğu kanaatindedir (Badri ve Badri, 2016). Sağl1k harcamaları hem özel sektörde hem de kamu sektöründe mevcut olan gelir veya kaynakların bir fonksiyonudur. Daha yüksek gelir, sağlık için harcanacak daha fazla para olduğu anlamına gelir. Sağlık ekonomisi içinde geniş bir araştırma grubu kişi başına sağlık harcamalarındaki değişimin, kişi başına düşen GSYİH'daki çeşitlilik ile açıklanabileceğini belirtmektedir (Gerdtham ve Jönsson, 2000). Bu amaçla, bu çalışma, 1976-2017 döneminde OECD’nin seçilmiş 17 ülkesi için sağlık harcamaları ve ekonomik büyüme arasındaki ilişkiyi panel veri yöntemleri kullanılarak araştırmaya çalışmaktadır.

Beşeri sermaye kişilerin sahip olduğu deneyim ve üretken yapısıyla ortaya koyulan ürün şeklinde de ifade edilmektedir. Bireylerin yetenek ve kabiliyetlerinin yükselmesiyle ortaya koyulan ürünün niteliğinin artmasına bu durumda beşeri sermayenin fiyatında bir yükseliş meydana gelmesine yol açacaktır (Thurow, 1970). 
Başta sağlık ve eğitim olmak üzere kişilerin hayat kalitesini yükselten pek çok unsur beşeri sermayenin esas belirleyicilerindendir. Bunun yanı sıra kişiler arasındaki güven bazlı meydana gelecek bağlantılar iktisadi bakımdan değerlendirilmektedir. Sosyal sermaye şeklinde değerlendirilen bu olgu uzmanlaşmayla beşeri sermayenin verimliliğinin yükselmesine yol açmaktadır (Karagül ve Masca, 2005).

Klasik okulunun en önemli temsilcisi Adam Smith "Milletlerin Zenginliği" adlı çalışmasında beşeri sermayeyi “yetişmiş insan gücü” şeklinde ifade etmiştir. İnsan gücünün niteliğinin yükselmesi için işbölümünün meydana gelmesi gerektiğinin üzerinde durmuştur. Sermaye birikiminin, sanayi kapitalizmin olmadığı kapalı sistemlerde iş gücünün ekonominin en temel üretim unsuru olduğunu ifade etmiştir. Endüstrileşen toplumlardaysa; işgücüyle beraber sermaye ve toprağın üretime katılması gerektiğini belirtmiştir (Smith, 2008: 5-45).

Ricardo, Smith'den farklı olarak işgücünü doğrudan üretimin bir unsuru şeklinde ifade ederken, sermayeyi dolaylı işgücü şeklinde ele almıştır. Üretilen malın değerini miktarından çok üretimde değerlendirilen emek miktarınca tespit edileceği ifade edilmiştir. Ricardo teknolojide oluşacak ilerlemeler neticesinde endüstride artan verimler yasasının geçerli olacağı konusu üzerinde durmuştur (Ricardo, 2008).

Marx, işgücünün niteliğinin artmasının üretilen ürünlerin de niteliğinin artmasına yol açacağı görüşünü öne sürmüştür. Marx, Ricardo’nun teknolojik ilerlemelerin üretimi iyi hale getireceği fikrini benimsemekle beraber, bu görüşün eksikliklerin bulunduğunu iddia etmiştir. Kişilerin sahip olduğu fiziki ve zihinsel kabiliyetlerin artmasının işgücünün en önemli belirleyicisi olduğunu iddia eden Marx, üretimde verimliliğin çoğalmasıyla daha az işgücü kullanılacağını ifade etmiştir (Marx, 1977).

Neo-klasiklerde beşeri sermaye konusunun üstünde durmuşlardır. Ekonomide gelirler ve giderler neticesinde meydana gelen fark1 "artık” şeklinde belirtmişlerdir. Ekonomide meydana gelen bu artığından beşeri sermayeden oluştuğunu iddia etmişlerdir (Çakmak ve Gümüş, 2005).

Neo-klasik büyüme modeli şeklinde de belirtilen Solow büyüme modeli 1956 senesinde öne sürülmüştür. Temelde işgücü ve sermayenin ikame girdiler olduğunu ve teknoloji seviyesinin sabit olduğunu ifade etmişlerdir. Cobb-Douglas türü üretim fonksiyonu baz alınmıştır. Üretim fonksiyonu aşağıdaki gibi ifade edilmiştir;

$$
\mathrm{Y}=\mathrm{f}(\mathrm{K}, \mathrm{L})=\mathrm{K}^{\mathrm{a}} \cdot \mathrm{L}^{1-\mathrm{a}}
$$

Teknolojinin sabit olduğu varsayımıyla çıktı miktarı; sermaye ve emek girdilerince tespit edilmektedir. Weil vd., Solow'un öne sürdüğü üretim fonksiyonuna beşeri sermayeyi de eklemiştir. Genişletilmiş Solow Modeli'nde, teknoloji ve beşeri sermaye değişkenleri denkleme eklenmiştir. 


$$
Y_{t}=K_{t}^{\alpha} H_{t}^{\beta}\left(A_{t} L_{t}^{\partial}\right)^{1-\alpha-\beta}
$$

Oluşturulan yeni denklemde;

A: teknolojik gelişme,

H: beşeri sermaye

şeklinde belirtilmektedir. Cobb-Douglas üretim fonksiyonu denklemine beşeri sermayenin ilave edilmesiyle üretimde işgücü, sermaye, teknoloji ve beşeri sermayenin ne derece etkili olacağı ifade edilmiştir (Mankiw vd., 1992).

Uluslararası Çalışma Örgütü (ILO) beşeri sermaye yatırımlarının çoğalmasıyla beraber ekonomide gelir dağılımının, büyümenin, ülke nüfusunda meydana gelen ilerlemelerin ve toplumsal yapının tepkilerinin etkileneceğini, bundan dolayı da beşeri sermayenin gerek mikro gerekse de makroekonomide etkili olabileceğini iddia etmiştir (ILO, 2004).

Sağlık başta olmak üzere çalışmaya ilişkin gerçekleştirilecek yatırımlar yeniliklerin meydana gelmesine destek olmaktadır. Bilhassa gelişmekte olan ülkelerde beşeri sermayede meydana gelen gelişmeler, teknolojik gelişmeye adapte olan gelişmiş ülkelerle rekabet etmek için önemli bir sektör görevi üstlenmektedir. Bilgi ve kabiliyetin tarım, sanayi, hizmet vb. sektörler haricinde sağllk ve iletişim gibi dallarda etkili biçimde değerlendirilmesi ülke ekonomisinde beşeri sermayenin önemini yükseltmektedir. Bilgi birikimin yüksek olduğu gelişmiş ülkelerde işbölümü katma değeri fazla olan alanlarda meydana gelmektedir. Bu durum karşısında az gelişmiş ülkeler katma değeri düşük pek çok alanda karşılaştırmalı bir üstünlük sunmaktadırlar. Gelişmekte olan bir ülkenin en azından o ülke için en uygun teknolojileri tespit edebilecek ve tespit eden teknolojileri de ülke şartlarına uyumlu olabilecek teknolojik ve beşeri sermayeye sahip olmalıdır (Şen ve Pehlivan, 2018).

Teknolojik ve beşeri sermayenin bileşenlerinin oluşum şeması Şekil 1'de gösterilmektedir. Sağlık, eğitim, hane halkı ve firmalara yapılacak yatırımların ardından beşeri sermayede artışlar meydana gelecektir. Teknolojik alt yapının sağlanmasıyla AR-GE, patent, inovasyon vb. alanlarda gelişim yaşanacaktır. Sosyal ve psikolojik faktörler yaratıcıllkla bütünleşerek teknolojik gelişime de destek olacaktır. Son olarak bütün faktörlerdeki etkileşim ekonomik kalkınmanın gelişimine neden olacaktır. 


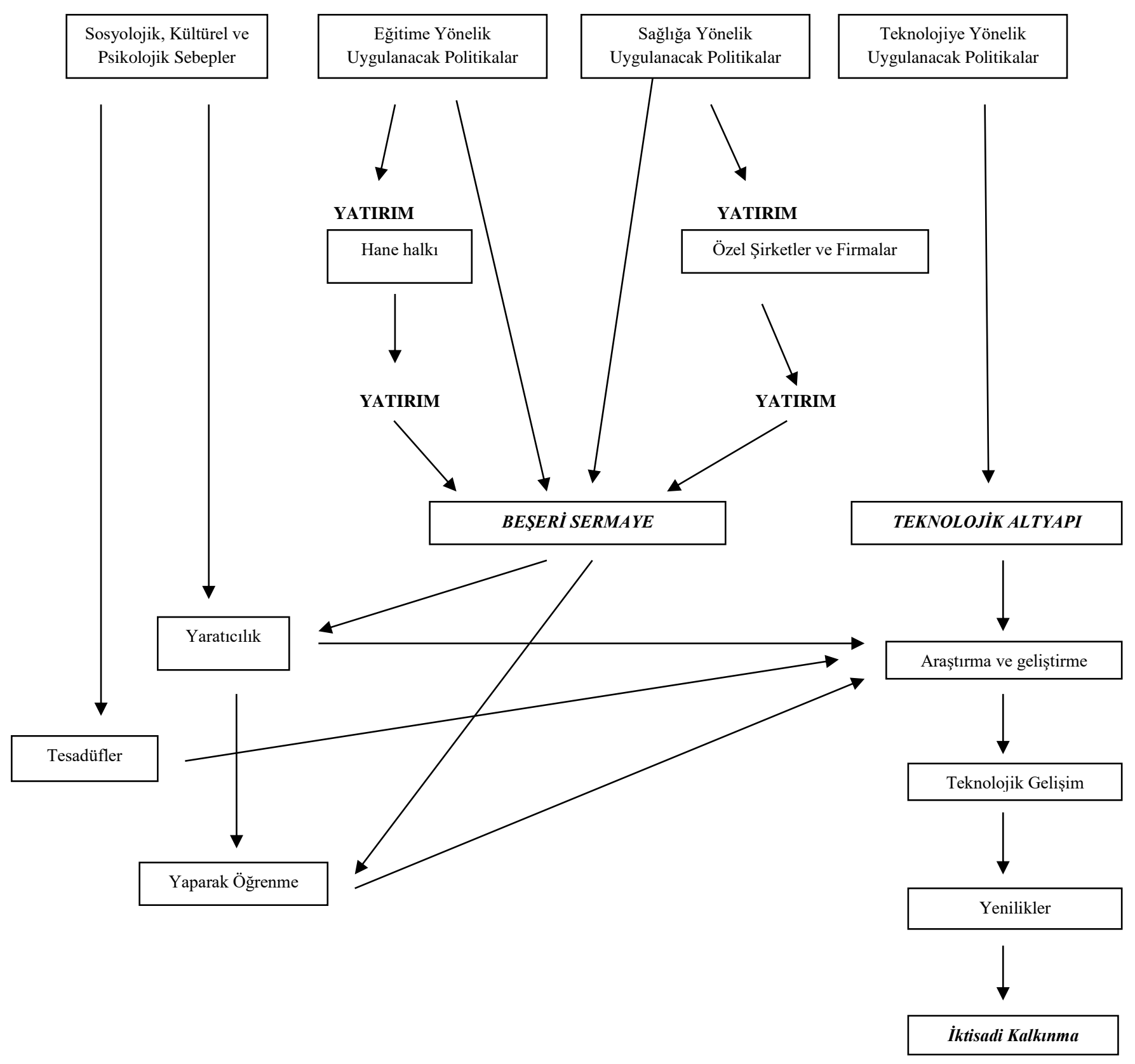

Şekil 1. Teknolojik ve Beşeri Sermayenin Belirleyicileri Kaynak: Kibritçioğlu, 1998.

\section{2. İlgili Literatür}

Literatürde sağlı harcamaları ve ekonomik büyüme arasındaki ilişkiyi sınamak için çeşitli ülke ya da ülke grupları için yapılmış birçok araştırma mevcuttur. Fakat ilişkinin durumu hakkında farklı ülke grupları için yapılan farklı analiz yöntemleri ile çeşitli sonuçlara ulaşıldığı görülmektedir. Burada amaç OECD ülkeleri için araştırma yapmak olduğu için sadece ilgili ülkü grupları literatür kapsamında dikkate alınmıştır. 
Tablo 1. Literatür Özeti

\begin{tabular}{|c|c|c|c|}
\hline Yazar(lar) & Dönem(ler) & Yöntem(ler) & Sonuç \\
\hline Heshmati (2001) & 1970-1992 & $\begin{array}{l}\text { Genişletilmiş Solow } \\
\text { Büyüme Modeli }\end{array}$ & $\begin{array}{l}22 \text { OECD ülkesinde sağlı, } \\
\text { ekonomik büyüme üzerinde pozitif } \\
\text { bir etkiye sahip ve ülkelerin } \\
\text { yakınsama hızı } \% 2.7\end{array}$ \\
\hline $\begin{array}{l}\text { Gerdtham ve } \\
\text { Löthgren (2000) }\end{array}$ & 1960-1997 & $\begin{array}{l}\text { Durağanlık ve } \\
\text { Eşbütünleşme Analizi }\end{array}$ & $\begin{array}{l}21 \text { OECD ülkesi için değişkenler } \\
\text { arasında ilişki mevcut }\end{array}$ \\
\hline $\begin{array}{l}\text { Gyimah-Brempong } \\
\text { ve Wilson (2004) }\end{array}$ & $1961-1995$ & $\begin{array}{l}\text { Genişletilmiş Solow } \\
\text { Büyüme Modeli }\end{array}$ & $\begin{array}{l}23 \text { OECD ülkesi için pozitif ve } \\
\text { güçlü bir etki }\end{array}$ \\
\hline $\begin{array}{l}\text { Dreger ve Reimers } \\
(2005)\end{array}$ & 1975- 2001 & Panel Eşbütünleşme Testi & $\begin{array}{l}21 \text { OECD ülkesi için uzun dönemli } \\
\text { bir eşbütünleşme ilişkisi }\end{array}$ \\
\hline $\begin{array}{l}\text { Koying ve Young- } \\
\text { Hsiang (2006) }\end{array}$ & $1980-1998$ & Panel Regresyon Analizi & $\begin{array}{l}15 \text { OECD ülkesi için uzun dönemli } \\
\text { bir ilişki }\end{array}$ \\
\hline Narayan vd. (2010) & $1974-2007$ & Eşbütünleşme Analizi & $\begin{array}{l}5 \text { Asya ülkesi için } \text { sağllk } \\
\text { harcamaları GDP üzerine } \\
\text { bir etkiye sahip }\end{array}$ \\
\hline Hartwig (2010) & $1970-2005$ & $\begin{array}{l}\text { Panel Nedensellik } \\
\text { Analizi }\end{array}$ & $\begin{array}{l}21 \text { OECD ülkesi için sağlık } \\
\text { harcamaları ekonomik büyümenin } \\
\text { nedeni değildir }\end{array}$ \\
\hline $\begin{array}{l}\text { Baltagi ve } \\
\text { Moscone (2010) }\end{array}$ & 1971-2004 & Panel Veri Analizi & $\begin{array}{l}20 \text { OECD ülkesi için } \text { sağlık } \\
\text { harcamalarının gerekli } \\
\text { sonucuna ulaşmışlardır }\end{array}$ \\
\hline $\begin{array}{l}\text { Çetin ve Ecevit } \\
\text { (2010) }\end{array}$ & 1990-2006 & Panel Regresyon Analizi & $\begin{array}{l}15 \text { OECD ülkesi için zayıf pozitif } \\
\text { ve istatistiki olarak anlamsız bir } \\
\text { ilişki }\end{array}$ \\
\hline Tatoğlu (2011) & $1975-2005$ & Panel Eşbütünleşme & $\begin{array}{l}20 \text { OECD ülkesi için değişkenler } \\
\text { arasında kısa dönem ve uzun } \\
\text { dönemde ilişki }\end{array}$ \\
\hline Pradhan (2011) & $1961-2007$ & $\begin{array}{l}\text { Panel Nedensellik } \\
\text { Analizi }\end{array}$ & $\begin{array}{l}11 \text { OECD ülkesi için çift yönlü bir } \\
\text { ilişki }\end{array}$ \\
\hline $\begin{array}{l}\text { Yardımcıoğlu } \\
(2012)\end{array}$ & $1975-2008$ & $\begin{array}{l}\text { Panel Eşbütünleşme Testi } \\
\text { ve Nedensellik Analizi }\end{array}$ & $\begin{array}{l}25 \text { OECD ülkesi için uzun } \\
\text { dönemde pozitif anlamlı bir ilişki } \\
\text { ve çift yönlü nedensellik }\end{array}$ \\
\hline Lago vd. (2012) & 1970-2009 & Panel Eşbütünleşme Testi & $\begin{array}{l}31 \text { OECD ülkesi için anlamlı bir } \\
\text { ilişki }\end{array}$ \\
\hline $\begin{array}{l}\text { Elmi ve Sadeghi } \\
\text { (2012) }\end{array}$ & 1990-2009 & $\begin{array}{l}\text { Panel Eşbütünleşme ve } \\
\text { Nedensellik }\end{array}$ & $\begin{array}{l}20 \text { gelişmekte olan ülke için kısa } \\
\text { dönemde tek yönlü, uzun dönemde } \\
\text { çift yönlü nedensellik ilişkisi }\end{array}$ \\
\hline Kumar (2013) & $1960-2007$ & $\begin{array}{l}\text { GMM ve Granger } \\
\text { Nedensellik }\end{array}$ & $\begin{array}{l}\text { Üye ülkeler arasında çift yönlü } \\
\text { nedensellik }\end{array}$ \\
\hline $\begin{array}{l}\text { Mehmood vd. } \\
(2014)\end{array}$ & $1990-2012$ & Panel Nedensellik & $\begin{array}{l}26 \text { Asya ülkesi için tek yönlü } \\
\text { nedensellik }\end{array}$ \\
\hline $\begin{array}{l}\text { Öztürk ve } \\
\text { Topçu (2014) }\end{array}$ & 1995-2012 & $\begin{array}{l}\text { Panel Eşbütünleşme ve } \\
\text { Nedensellik }\end{array}$ & $\begin{array}{l}\text { G8 ülkeleri için tek yönlü } \\
\text { nedensellik }\end{array}$ \\
\hline $\begin{array}{l}\text { Badri ve Badri } \\
(2016)\end{array}$ & 2006-2013 & GMM yöntemi & $\begin{array}{l}24 \text { OECD ülkesi için için pozitif ve } \\
\text { anlamlı bir ilişki }\end{array}$ \\
\hline
\end{tabular}




\begin{tabular}{lll}
\hline Fazaeli vd. (2016) 1995-2012 Panel Eşbütünleşme & $\begin{array}{l}12 \text { petrol ihracatçısı ülkeleri için } \\
\text { değişkenler arasında güçlü ilişki }\end{array}$ \\
\hline
\end{tabular}

\section{Veri seti ve yöntem}

$\mathrm{Bu}$ çalışmada seçilmiş 17 OECD ülkesi için (Avusturya, Belçika, Kanada, Danimarka, Almanya, İzlanda, İrlanda, Lüksemburg, Hollanda, Norveç, Portekiz, İspanya, İsveç, İsviçre, Türkiye, Birleşik Krallık ve Amerika Birleşik Devletleri) sağlık harcamaları ve ekonomik büyüme arasındaki ilişki incelenmek istenmektedir. Yıllık veriler 1976-2017 dönemini kapsamaktadır. Ekonomik büyüme serisi için ve sağlık harcamaları serisi için veriler sırasıyla Dünya Bankası resmi veri tabanından ve OECD resmi veri tabanından derlenmiştir. Panel eşbütünleşme testinden önce serilerin durağanlığı sınanmıştır. Bu amaçla serilere Levin, Lin ve Chu (LLC, 2002), Im, Pesaran ve Shin (IPS, 2003), Fisher-ADF (1999) ve Fisher-PP (1999) testleri uygulanmıştır. Hatemi-J (2018) tarafından literatüre kazandırılan saklı panel eşbütünleşme yöntemi ile seriler arasındaki uzun dönemli ilişki incelenmiştir. Ardından seriler arasındaki nedensellik ilişkisi incelenmek istenmiştir ve asimetrik panel nedensellik testi ile serilerin kendileri ve şokları arasındaki nedensel ilişki ortaya çıkarılmaya çalışılmıştır.

\subsection{Saklı panel eşbütünleşme testi (Hatemi-J, 2018)}

$\mathrm{Bu}$ test Hatemi-J (2018) tarafından önerilmiştir. Panel Kao eşbütünleşme testine dayanmaktadır. Hatemi-J (2018) serileri pozitif ve negatif bileşenlerine ayırdıktan sonra, Kao (1999)'nın önerdiği testi uygulamaktadır. Eşbütünleşme analizi yapılabilmesi için serilerin birinci dereceden durağan olması şartı vardır. Eşbütünleşme ilişkisinin olmadığı sıfır hipotezi altında test sürecini tamamlamaktadır. Birinci dereceden bütünleşik iki değişken için;

$$
\begin{aligned}
& y_{i, t}=y_{i, t-1}+e_{i 1, t}=y_{i, 0}+\sum_{j=1}^{t} e_{i 1, j}, i=1,2, \ldots, m \\
& x_{i, t}=x_{i, t-1}+e_{i 2, t}=x_{i, 0}+\sum_{j=1}^{t} e_{i 2, j}, i=1,2, \ldots, m
\end{aligned}
$$

Burada m, yatay kesitsel boyutu belirtir ve $e$, beyaz gürültü süreci olarak kabul edilen bozucu terimidir. Her panel değişkeni için pozitif ve negatif şoklar aşağıdaki gibidir:

$$
\begin{aligned}
& e_{i 1, t}^{+}=\operatorname{Max}\left(e_{i 1, t}, 0\right) \\
& e_{i 2, t}^{+}=\operatorname{Max}\left(e_{i 2, t}, 0\right) \\
& e_{i 1, t}^{-}=\operatorname{Min}\left(e_{i 1, t}, 0\right) \\
& e_{i 2, t}^{-}=\operatorname{Min}\left(e_{i 1, t}, 0\right)
\end{aligned}
$$

Bu sonuçları kullanarak aşağıdaki ifadeler elde edilebilir:

$$
\begin{aligned}
& y_{i, t}^{+}=y_{i, 0}^{+}+e_{i 1, t}^{+}=y_{i, 0}+\sum_{j=1}^{t} e_{i 1, j}^{+} \\
& x_{i, t}^{+}=x_{i, 0}^{+}+e_{i 2, t}^{+}=x_{i, 0}+\sum_{j=1}^{t} e_{i 2, j}^{+}
\end{aligned}
$$




$$
\begin{aligned}
& y_{i, t}^{-}=y_{i, 0}^{-}+e_{i 1, t}^{-}=y_{i, 0}+\sum_{j=1}^{t} e_{i 1, j}^{-} \\
& x_{i, t}^{-}=x_{i, 0}^{-}+e_{i 2, t}^{-}=x_{i, 0}+\sum_{j=1}^{t} e_{i 2, j}^{-}
\end{aligned}
$$

$y$ bağımlı değişkeni göstermek üzere, pozitif ve negatif bileşenler için iki panel eşbütünleşme denkemi aşağıdaki gibi verilsin:

$$
\begin{aligned}
& y_{i, t}^{+}=\alpha_{i}^{+}+\beta_{i}^{+} x_{i, t}^{+}+e_{i, t}^{+} \\
& y_{i, t}^{-}=\alpha_{i}^{-}+\beta_{i}^{-} x_{i, t}^{-}+e_{i, t}^{-}
\end{aligned}
$$

(7) ve (8) denklemlerinde sırasıyla $e_{i, t}^{+}$ve $e_{i, t}^{-}$durağan ise, pozitif ve negatif kümülatif şoklar eşbütünleşiktir. Daha sonra $e_{i, t}^{+}$ve $e_{i, t}^{-}$şoklarının durağan olup olmadığı genişletilmiş DickeyFuller (ADF) testi ile sınanır. (7) denklemi için panel ADF test denklemi aşağıdaki gibi olur:

$$
e_{i, t}^{+}=\rho^{+} e_{i, t-1}^{+}+\sum_{l=1}^{k} \gamma_{i}^{+} \Delta e_{i 1, t-1}^{+}+w_{i, t}^{+}
$$

Uygun gecikme mertebesi $l$, bir bilgi kriterinin minimizasyonu ile belirlenebilir. $\rho^{+}=0$ sifir hipotezinin sınanması ile pozitif bileşenler arasında eşbütünleşme olup olmadığına karar verilir.

Kao panel eşbütünleşme sıfır hipotezini test etmek için aşağıdaki test istatistiği kullanılabilir:

$$
A D F=\frac{t^{+}+\sqrt{6} \times \frac{\sigma_{v}}{2 \sigma_{0 v}}}{\sqrt{\frac{\sigma_{0 v}^{2}}{2 \sigma_{v}^{2}}+\frac{3 \sigma_{v}^{2}}{10 \sigma_{0 v}^{2}}}}
$$

Burada $t_{\rho^{+}},(7)$ denklemindeki $\rho^{+}$parametresinin $t$ istatistiğidir. $\sigma_{v}^{2}$ ve $\sigma_{0 v}^{2}$ sirasiyla varyans ve uzun dönemli varyansı temsil etmektedir. Ayrıca (10) denklemi standart normal dağılıma sahiptir. Uzun dönem varyans-kovaryans matrisi, kernel tahmini yaklaşımı ile aşağıdaki gibidir:

$$
\Omega=\left[\begin{array}{cc}
\sigma_{e_{1}^{+}}^{2} & \sigma_{e_{1}^{+}, e_{2}^{+}}^{2} \\
\sigma_{e_{1}^{+}, e_{2}^{+}}^{2} & \sigma_{e_{2}^{+}}^{2}
\end{array}\right]=\frac{1}{m} \sum_{i=1}^{m}\left[\frac{1}{T} \sum_{i=1}^{T} u_{i t} u_{i t}^{\prime}+\frac{1}{T} \sum_{i=1}^{T} \mathcal{K}(\tau / b) \sum_{\mathrm{t}=\tau+1}^{T}\left(u_{i t} u_{i t-\tau}^{\prime}+u_{i t-\tau} u_{i t}^{\prime}\right)\right]
$$

Burada $\mathcal{K}$ kernel fonksiyonunu ve $b$ bant genişliğini göstermektedir. Aynı test süreci negatif bileşenler içinde sürdürülebilir. Ayrıca pozitif bileşenlerden negatif bileșenlere ya da negatif bileşenlerden pozitif bileşenlere de eş bütünleşme süreci aynıdır (Hatemi-J, 2018: 508-509).

\subsection{Asimetrik nedensellik}

Literatürde, bir panel veri metodolojisinde Granger (1969) nedenselliği test etmek amacıyla çok sayıda yöntem mevcuttur. Ancak, bu testler asimetrik nedensel etkilere izin vermediğinden pozitif ve negatif şokların etkisini dikkate almamaktadır. Asimetrik bilginin kullanılması Akerlof (1970), Spence (1973) ve Stiglitz (1974)'nin çalışmalarından sonra yaygınlaşmaya başlamıştır. Makroekonomik değişkenlerin pozitif olanlara kıyasla negatif değişime daha fazla tepki verme eğilimindedir. Dolayısıyla nedensellik testleri uygulandığında potansiyel asimetrik etkilerin dikkate alınması önemlidir (Hatemi-J vd., 2014). Bu kısımda (3), (4), (5) ve (6) 
denklemleri için pozitif ve negatif şoklar arasındaki nedensellik ilişkisi $p$ gecikmeli vektör otoregresif (VAR) modeli kullanılarak test edilmektedir. Pozitif şokların $y^{+}=\left(y_{1, t}^{+}, y_{2, t}^{+}\right)$ şeklinde gösterilecek olursa, VAR (p) modeli aşağıdaki gibi yazılır:

$$
y^{+}=\delta+A_{1} y_{t-1}^{+}+A_{2} y_{t-2}^{+}+\cdots A_{p} y_{t-p}^{+}+e_{t}^{+}
$$

ya da en geniş hali ile;

$$
\left[\begin{array}{l}
y_{1, t}^{+} \\
y_{2, t}^{+}
\end{array}\right]=\left[\begin{array}{l}
\delta_{1 t} \\
\delta_{2 t}
\end{array}\right]+\left[\begin{array}{ll}
\beta_{11} & \beta_{12} \\
\beta_{21} & \beta_{22}
\end{array}\right]\left[\begin{array}{c}
Y_{1 t-1} \\
y_{2, t-1}^{+}
\end{array}\right]+\left[\begin{array}{c}
e_{1, t}^{+} \\
e_{2, t}^{+}
\end{array}\right]
$$

şeklindedir. Testin sıfır hipotezi $y_{i 2, t}^{+}, y_{i 1, t}^{+}$'nin nedeni değildir şeklinde kurulmaktadır ve $\beta_{i 2, r}$ katsayısı Wald test istatistiği ile hesaplanmaktadır (Hatemi-J, 2012). Negatif bileşenler için işlem süreci aynı şekildedir.

\section{Ampirik Sonuçlar}

Bir toplumun ekonomik ve sağlık düzeyi açısından gelişmişliği arasında yakın bir ilişki mevcuttur. Bu ilişkinin temelinde insan olduğu için bu konu araştırmacıların hep ilgi odağ olmuştur. Bu amaçla seçilmiş 17 OECD ülkesi için sağlık harcamaları ve ekonomik büyüme arasındaki asimetrik eşbütünleşme ve aralarındaki asimetrik nedensellik ilişkisi araştırılmıştır. $\mathrm{Bu}$ amaçla öncelikle paneldeki her bir değişkenin bir birim kök içerip içermediği araştırılır. Bunun için serilerin durağanlık sınaması LLC, IPS, Fisher-ADF ve Fisher-PP testleri uygulanmıştır. Sonuçlar Tablo 2'de ve Tablo 3’te sunulmuştur.

Tablo 2. Panel Birim Kök Test Sonuçları

\begin{tabular}{lccccc}
\hline & & LLC & IPS & Fisher-ADF & Fisher-PP \\
\hline \multirow{2}{*}{ Sabitli } & $H E$ & $-0.546(0.293)$ & $3.468(0.998)$ & $13.403(0.994)$ & $11.292(0.997)$ \\
\cline { 2 - 6 } & $G D P$ & $-0.691(0.245)$ & $2.233(0.987)$ & $16.266(0.980)$ & $41.334(0.181)$ \\
\hline Sabitli ve Trendli & $H E$ & $-0.427(0.335)$ & $0.0837(0.533)$ & $33.693(0.483)$ & $16.9618(0.950)$ \\
\hline \multirow{2}{*}{ Sabitli } & $G D P$ & $-0.169(0.433)$ & $1.243(0.893)$ & $25.454(0.854)$ & $13.946(0.998)$ \\
\hline \multirow{2}{*}{ Sabitli ve Trendli } & $\Delta H E$ & $-13.121(0.000)^{*}$ & $-13.580(0.000)^{*}$ & $239.035(0.000)^{*}$ & $375.831(0.000)^{*}$ \\
\cline { 2 - 6 } & $\Delta G D P$ & $-11.501(0.000)^{*}$ & $-11.071(0.000)^{*}$ & $188.771(0.000)^{*}$ & $241.353(0.000)^{*}$ \\
\cline { 2 - 6 } & $\Delta H E$ & $-11.864(0.000)^{*}$ & $-11.827(0.000)^{*}$ & $191.543(0.000)^{*}$ & $439.145(0.000)^{*}$ \\
\hline
\end{tabular}

Not: *, \% 1 anlamlılık düzeyini ifade etmektedir. Parantez içindeki değerler serilerin olasılık değerleridir.

Tablo 3. Değişkenlerin Şoklarının Panel Birim Kök Test Sonuçları

\begin{tabular}{lccccc}
\hline & & LLC & IPS & Fisher-ADF & Fisher-PP \\
\hline \multirow{2}{*}{ Sabitli } & $H E^{+}$ & $-0.316(0.376)$ & $5.476(0.995)$ & $9.101(0.997)$ & $11.170(0.999)$ \\
\cline { 2 - 6 } & $G D P^{+}$ & $0.699(0.758)$ & $7.093(0.999)$ & $3.978(0.998)$ & $4.073(0.996)$ \\
\hline Sabitli ve Trendli & $H E^{+}$ & $-1.322(0.093)$ & $-0.427(0.335)$ & $39.915(0.224)$ & $22.701(0.894)$ \\
\hline \multirow{2}{*}{ Sabitli } & $G D P^{+}$ & $-1.531(0.063)$ & $-0.806(0.210)$ & $42.445(0.152)$ & $14.408(0.994)$ \\
\hline & $H E^{-}$ & $0.878(0.810)$ & $5.251(0.996)$ & $9.060(0.998)$ & $9.936(0.997)$ \\
\cline { 2 - 6 } & $G D P^{-}$ & $2.543(0.994)$ & $5.294(0.998)$ & $4.399(0.999)$ & $2.980(0.998)$ \\
\hline
\end{tabular}




\begin{tabular}{llllll}
\hline Sabitli ve Trendli & $G D P^{-}$ & $0.599(0.725)$ & $1.137(0.872)$ & $21.941(0.881)$ & $16.333(0.985)$ \\
\hline \multirow{2}{*}{ Sabitli } & $\Delta H E^{+}$ & $-13.502(0.000)^{*}$ & $-13.863(0.000)^{*}$ & $245.398(0.000)^{*}$ & $366.708(0.000)^{*}$ \\
\cline { 2 - 6 } & $\Delta G D P^{+}$ & $-9.142(0.000)^{*}$ & $-10.634(0.000)^{*}$ & $179.856(0.000)^{*}$ & $197.517(0.000)^{*}$ \\
\hline Sabitli ve Trendli & $\Delta H E^{+}$ & $-12.425(0.000)^{*}$ & $-12.339(0.000)^{*}$ & $199.759(0.000)^{*}$ & $603.660(0.000)^{*}$ \\
\cline { 2 - 6 } & $\Delta G D P^{+}$ & $-7.725(0.000)^{*}$ & $-8.926(0.000)^{*}$ & $141.204(0.000)^{*}$ & $167.905(0.000)^{*}$ \\
\hline \multirow{2}{*}{ Sabitli } & $\Delta H E^{-}$ & $-10.568(0.000)^{*}$ & $-12.434(0.000)^{*}$ & $215.228(0.000)^{*}$ & $378.386(0.000)^{*}$ \\
\hline \multirow{2}{*}{ Sabitli ve Trendli } & $\Delta G D P^{-}$ & $-12.125(0.000)^{*}$ & $-12.352(0.000)^{*}$ & $211.436(0.000)^{*}$ & $328.931(0.000)^{*}$ \\
\cline { 2 - 6 } & $\Delta H E^{-}$ & $-9.175(0.000)^{*}$ & $-10.339(0.000)^{*}$ & $163.159(0.000)^{*}$ & $377.432(0.000)^{*}$ \\
\hline
\end{tabular}

Not: *, \% 1 anlamlılık düzeyini ifade etmektedir. Parantez içindeki değerler serilerin olasılık değerleridir.

$\mathrm{Bu}$ sonuçlara göre serilerin hem kendilerinin hem de pozitif ve negatif şoklarının düzey değerlerinde birim köklü yapıda olduğu görülmüştür. Fakat farkı alındıktan sonra serilerin durağan hale gelmektedir. Özetle seriler birinci dereceden bütünleşiktir yani I(1)'dir.

Tablo 4. Saklı Panel Eşbütünleşme Test Sonuçları

\begin{tabular}{cl}
\hline Değişkenler & $H_{0}: I(1), H_{1}: I(0)$ \\
\hline$(H E, G D P)$ & $-1.244(0.107)$ \\
\hline$\left(H E^{+}, G D P^{+}\right)$ & $-2.285(0.011)^{* *}$ \\
\hline$\left(H E^{-}, G D P^{-}\right)$ & $-3.281(0.005)^{*}$ \\
\hline$\left(H E^{-}, G D P^{+}\right)$ & $-2.908(0.001)^{*}$ \\
\hline$\left(H E^{+}, G D P^{-}\right)$ & $-2.839(0.002)^{*}$
\end{tabular}

NOT: * ve ** sırasıyla \% 1 ve \% 5 düzeyinde anlamlılığ 1 ifade etmektedir. Parantez içindeki değerler olasılık değerleridir.

Paneldeki her bir değişken birinci dereceden bütünleşik olduğu için seriler arasında eşbütünleşme ilişkisi Hatemi-J (2018) tarafindan önerilen test ile araştırılmaktadır. Tablo 4'te sunulan eşbütünleşme analiz test sonuçlarına göre serilerin standart durumlarında eş bütünleşme ilişkisi yok iken, bileşenler arasında panel eşbütünleşme ilişkisinin olduğu görülür.

Tablo 5. Simetrik ve Asimetrik Panel Nedensellik Test Sonuçları

\begin{tabular}{cc}
\hline$H E \nrightarrow G D P$ & $1.615(0.352)$ \\
\hline$G D P \nrightarrow H E$ & $3.908(0.0012)^{*}$ \\
\hline$H E^{+} \nrightarrow G D P^{+}$ & $1.530(0.276)$ \\
\hline$G D P^{+} \nrightarrow H E^{+}$ & $1.955(0.753)$ \\
\hline$H E^{-} \nrightarrow G D P^{-}$ & $0.935(0.0303)^{* *}$ \\
\hline$G D P^{-} \nrightarrow H E^{-}$ & $0.246(0.0006)^{*}$ \\
\hline
\end{tabular}

Not: * ve ** sırasıyla \% 1 ve \% 5 düzeyinde anlamlılığı ifade etmektedir.
Parantez içindeki değerler
olasılık değerleridir. Y^X: Sğlık harcamaları GDP’nin nedeni değildir.

Panel nedensellik test sonuçlarına göre, ekonomik büyümeden sağlık harcamalarına doğru tek yönlü bir nedensel ilişki görülmektedir. Sağlık harcamalarındaki pozitif bir şokun ekonomik büyümedeki pozitif şok ile karşılıklı olarak nedensellik ilişkisi olmadığı bulgusuna ulaşılmıştır. Bunun aksine negatif şoklar arasında çift yönlü bir nedensellik ilişkisi olduğu tespit edilmiştir. 
Dolayısıyla ekonomik büyümede meydana gelebilecek negatif şokların sağlık harcamaları üzerinde negatif şoklara neden olacağı anlaşılmaktadır.

\section{Sonuç ve Değerlendirme}

$\mathrm{Bu}$ çalışma OECD ülkelerindeki sağlık harcamaları ve gelir arasındaki uzun dönemli ve nedensel ilişkiyi araştırmıştır. 1976-2017 dönemlerinde 17 OECD ülkesinden oluşan bir panel veri seti kullanıldı ve sağlık harcamalarının ve GSYİH'nın öncelikle panel durağanlık sınamaları yapıldı. Seriler birinci dereceden bütünleşik olduğundan uzun dönem ilişkisi literatüre yeni kazandırılan Hatemi-J (2018) saklı eşbütünleşme testi ile yapıldı. Ardından serilerin şokları arasındaki nedensellik ilişkisi sınandı. Sonuçlara göre GDP'nin güçlü bir dışsal değişken olduğu görülmektedir. Serilerin standart halleri arasında ekonomik büyümeden sağlık harcamalarına doğru tek yönlü nedensel ilişki bulunmuştur. Sağlık harcamalarından ekonomik büyümeye doğru nedensel bir ilişkinin bulunmaması insanın sağlık olgusunun hiçe sayılması anlamına gelmemektedir. Zaten negatif şoklarda çift yönlü bir ilişkinin bulunması bunu kanitlamaktadir.

Çalışma kapsamında elde edilen bulguları, OECD ülkeleriyle gerçekleştirilen diğer araştırmaların sonuçlarıyla kıyaslamak mümkündür. Heshmati (2001), 1970-1992 döneminde genişletilmiş Solow modeli kapsamında sağlıkla ekonomik büyüme arasındaki nedensellik ilişkisini incelemiştir. Çalışma, sağlığın ekonomik büyümede nedensel bir etkisinin bulunduğunu ispatlamaktadır. Solow modelini ele alarak toplam sağlık harcamalarının kişi başına gelir artışındaki etkisini Afrika ve OECD ülkelerinde inceleyen Gyimah ve Wilson (2004) ise sağlık harcamalarının tamamının kişi başına gelir artışında pozitif ve güçlü bir etkisi olduğu bulgusunu elde etmiştir. Öte yandan, 21 OECD ülkesini inceleyen Dreger ve Reimers (2005), 1975-2001 dönemi için yeni panel eşbütünleşme yöntemlerini ele almış, sağlık ve ekonomik büyüme arasında bir eşbütünleşme ilişkisi olduğu sonucunu elde etmiştir. Ayrıca, 15 OECD ülkesi ile çalışan Koying ve Young-Hsiang (2006), sağlık harcamaları ve ekonomik büyüme arasında pozitif ve istatistiksel olarak anlamlı bir ilişki olduğu bulgusunu elde etmiştir. $\mathrm{Bu}$ araştırmalar, sağlığın ekonomik büyüme üzerindeki temel belirleyicilerden olduğunu ispatlar özelliktedir.

Sağlık olgusundaki iyileşmeler, büyüme üzerinde hiçbir etkiye sahip olmasa bile insan hayatının söz konusu olduğu durumda çabaya değer olacaktır. Dolayısıyla hem sürdürülebilir bir ekonomik büyüme için sağlığa yönelik politika uygulamalarına ağırlık verilmeli hem de insan değerli olduğu için keyfiyetten ziyade zorunluluk olduğu göz önünde bulundurulmalıdır. 


\section{KAYNAKÇA}

Akerlof, George A. 1970. The Market for "lemons": Quality Uncertainty and the Market Mechanism. Quarterly Journial of Economics, 84: 488-500.

Ağır, H., ve Tıraş, H. H. (2018). Sağlık Harcamaları ve Ekonomik Büyüme İlişkisi: Panel Nedensellik Analizi. Gaziantep University Journal of Social Sciences, 17(4), 1558-1573.

Antonio, J. ve Zamora, C. (2000). Investment in Health and Economic Growth: A Perspective from Latin America and the Caribbean. XXXV Meeting of The Advisory Committe on Health Research, Havana, Cuba, 17 19 July, Division of Health and Human Development, Washington, DC.

Badri, A. K. ve Badri, S. K. (2016). Health Spending and Economic Growth in Selected OECD Countries. AIS (American Institute of Science), American Journal of Clinical Neurology and Neurosurgery, 2(1), 5-9.

Baltagi, H., Badi ve Moscone, F. (2010). Health Care Expenditure and Income in the OECD Reconsidered: EvidenceFrom Panel Data. IZA DiscussionPaper.

Çakmak, E. ve Gümüş, S. (2005). Türkiye'de Beşeri Sermaye ve iktisadi büyüme: Ekonometrik Bir Analiz (19602002), Ankara Üniversitesi, Siyasal Bilgiler Fakültesi Yayınları, Sayı:60, 59-72.

Çetin, M. ve Ecevit, E. (2010). Sağlık Harcamalarının Ekonomik Büyüme Üzerindeki Etkisi: OECD Ülkeleri Üzerine Bir Panel Regresyon Analizi. Doğuş Üniversitesi Dergisi, 11(2), 166-182.

Dreger, C. ve Reimers, H. E. (2005). Health Care Expenditures in OECD Countries: A Panel Unit Root and Cointegration Analysis. IZA Discussion Paper, 1469, 1-20.

Elmi, Z. M. ve Sadeghi, S. (2012). Health Care Expenditures and Economic Growth in Developing Countries: Panel Cointegration and Causality. Middle-East Journal of Scientific Research, 12(1), 88-91.

Fazaeli, A. A., Ghaderi, H., Salehi, M. ve Fazaeli, A. R. (2016). Health Care Expenditure and GDP in Oil Exporting Countries: Evidence From OPEC Data, 1995-2012. Global Journal of Health Science, 8(2), 93-98.

Gerdtham, U.G. ve M. Löthgren. (2000). On Stationary and Cointegration of International Health Care Expenditure and GDP. Journal of Health Economics, 19, 461-475.

Gerdtham, U. G., ve Jönsson, B. (2000). International Comparisons of Health Expenditure: Theory, Data And Econometric Analysis. In Handbook of Health Economics (Vol. 1, pp. 11-53). Elsevier.

Granger, C. W. (1969). Investigating Causal Relations by Econometric Models and Cross-Spectral Methods. Econometrica: journal of the Econometric Society, 424-438.

Gyimah-Brempong, K. ve Wilson, M. (2004). Health Human Capital and Economic Growth in SubSaharan African and OECD Countries. The Quarterly Review of Economics and Finance, 44(2), 296-320.

Hartwig, J. (2010). Is Health Capital Formation Good for Long-term Economic Growth? Panel Granger Causality Evidence for OECD Countries. Journal of Macroeconomics, 32, 314-325.

Hatemi-J, A. (2012). Asymmetric Causality Tests with an Application. Empirical Economics, 43(1), 447-456.

Hatemi-J, A., Gupta, R., Kasongo, A., Mboweni, T. ve Netshitenzhe, N. (2014). Are There Asymmetric Causal Relationships Between Tourism and Economic Growth in a Panel of G-7 Countries. University of Pretoria, Department of Economics Working Paper, 76, 1-18.

Hatemi-J, A. (2018). Hidden Panel Cointegration. Journal of King Saud University - Science 32 (2020), 507-510.

Heshmati, A. (2001). On the Causality between GDP and Health Care Expenditure in Augmented Solow Growth Model. SSE/EFI Working Paper Series in Economics and Finance, 423, 1-19.

ILO, (2004). Investing in Every Child: An Economic Study of the Costs and Benefits of Eliminating Child Labour. Geneva.

Im, K. S., Pesaran, M. H. ve Shin, Y. (2003). Testing for Unit Roots in Heterogeneous Panels. Journal of Econometrics, 115(1), 53-74.

Kao, C. (1999). Spurious Regression and Residual-based Tests for Cointegration in Panel Data. J. Econometrics 90, 1-44.

Karagül, M. ve Masca, M. (2005). A Literature Review on Social Capital. Ekonomik ve Sosyal Araştırmalar Dergisi https://dergipark.org.tr/tr/pub/esad/issue/6046/81344.

Kibritçioğlu, A. (1998). İktisadi Büyümenin Belirleyicileri ve Yeni Büyüme Modellerinde Beşeri Sermayenin Yeri. Ankara Üniversitesi Siyasal Bilgiler Fakültesi Dergisi, 53: 1-4, 207-230.

Koying, C. ve Young-Hsiang, Y. (2006). Economic Growth, Human Capital İnvestment, and Health Expenditure: A Study of OECD Countries. Hitotsubashi Journal of Economics, 47(1), 1-16.

Kumar, S. (2013). Systems GMM Estimates of the Health Care Spending and GDP Relationship: A Note. The European Journal of Health Economics, 14(3), 503-506.

Lago-Peñas, S., Cantarero, D. ve Blázquez, C. (2012), On the Relationship between GDP and Health Care Expenditure: A New Look, Economic Modelling, 124-129.

Levin, A., Lin, C. F., ve Chu, C. S. J. (2002). Unit Root Tests in Panel Data: Asymptotic and Finite-Sample Properties. Journal of Econometrics, 108, 1-24.

Lustig, N. (2006). Investing in Health for Economic Development: The Case of Mexico. UNU-WIDER Research Paper No. 2006/30, 1-19. 
Maddala, G. S., ve Wu, S. (1999). A Comparative Study of Unit Root Tests with Panel Data and a New Simple Test. Oxford Bulletin of Economics and statistics, 61(S1), 631-652.

Mankiw, N. G., Romer D., Weil, D.N., (1992). A Contribution to the Empirics of Economic Growth, Quarterly Journal of Economics, Vol:107, No. 2, (May 1992), 407-437.

Marx, K. (1977). CAPITAL, Lawrence and Wishart, London.

Mehmood, B., Raza, S. H. ve Mureed, S. (2014). Health Expenditure, Literacy and Economic Growth: PMG Evidence From Asian Countries. Euro-Asian Journal of Economics and Finance, 2(4), 408-417.

Narayan, S., Narayan, P. K. ve Mishra, S. (2010). Investigating The Relationship between Health and Economic Growth: Empirical Evidence From A Panel of 5 Asian Countries. Journal of Asian Economics, 21(4), 404-411.

Öztürk, S. ve Topçu, E. (2014). Health Expenditures and Economic Growth: Evidence from G8 Countries. International Journal of Economics and Empirical Research, 2(7), 262- 267.

Pradhan, R.P. (2011). Effects of Health Spending on Economic Growth: A Time Series Approach. Decision, 38(2), 68-83.

Ricardo, D. (2008). Siyasal İktisadın ve Vergilendirmenin İlkeleri, Çev.: B.ZEREN, T. İş Bankası Kültür Yayınları, Birinci Basım, İstanbul.

Smith, A. (2008). Milletlerin Zenginliği, Çeviren: Haldun DERİN, Türkiye İş Bankası Kültür Yayınları, 2.Baskı, İstanbul.

Spence, M. (1973). Job Market Signaling, Quarterly Journal of Economics, 87(3), 355-374.

Stiglitz, J. E. (1974). Growth with Exhaustible Natural Resources, Review of Economi Studies.

Şen, A. ve Pehlivan, C. (2018). Türkiye ve Brics Ülkelerinde Teknoloji ve Beşeri Sermayenin Ekonomideki Etkinliği: Panel Veri Analizi, Fiscaoeconomia, Vol.2(3): 198-225, DOI: 10.25295/fsecon.2018.03.009.

Thurow, Lester, C., (1970). Investment in Human Capital, Wards Worth Publishing Company, California.

Yardımcıoğlu, F. (2012). OECD Ülkelerinde Sağlık ve Ekonomik Büyüme İlişkisinin Ekonometrik Bir İncelemesi. Eskişehir Osmangazi Üniversitesi Sosyal Bilimler Dergisi, 13(2), 27-47.

Yerdelen Tatoğlu, F. (2011). The Relationships between Human Capital Investment and Economic Growth: A Panel Error Correction model. Joumal of Economic and Social Research, 13(1), 75-88.

Yılmaz, Z. ve Danışoğlu, F. (2017). Ekonomik Kalkınmada Beşerî Sermayenin Rolü ve Türkiye'de Beşerî Kalkınmanın Görünümü Olarak İnsani Gelişim Endeksi. Dumlupınar Üniversitesi Sosyal Bilimler Dergisi, 1 (51), 117-147. 